\title{
BENTUK PENYAJIAN ANSAMBEL GONDANG SABANGUNAN \\ PADA UPACARA PANANGKOK SARING-SARING DI DESA \\ PATOR JANJI MATOGU KECAMATAN ULUAN \\ KABUPATEN TOBA SAMOSIR
}

\author{
Fenny Hannatasya Purba \\ Prodi PendidikanMusik
}

\begin{abstract}
The results showed that the presence of Gondang Sabangunan in the village Partor Janji Matogu important role in any traditional events in the village Partor Janji Matogu which can be seen from the function, especially in traditional events Panangkok Saringsaring to accompany tortor when dropping crates to the location of the tomb new, accompany tortor the hula when handing rudang-rudang and accompany tortor bona hasuhutan that will bring rudang-rudang into the house. Forms of presentation gondang played using ensemble gondang Sabangunan, this ensemble plays a repertoire gondang sipitu in the event panangkok Saring-saring is Gondang At first, Gondang somba-somba, Gondang mangaliat, Gondang Pasu-pasu, Gondang sahata saoloan, Gondang hasahaton, Gondang sitiotio , Gondang Sipitu particular musical form gondang mangaliat accentuate the melody played by Bolon sarune musical instruments and other musical instruments taganing, ogung, hesek serves as an accompaniment melody and tempo beats with a value thatisdifferent foreach instrument.
\end{abstract}

Keywords: Presentation Form, ensemble Gondang Sabangunan, Panangkok Saringsaring. 


\section{PENDAHULUAN}

Kebudayaan indonesia di zaman modern ini sangat jauh tertinggal bahkan hamper punah dikarenakan masuknya kebudayaan-kebudayaan barat yang telah menghipnotis para pemuda sebagai penerus bangsa indonesia, kebudayaan merupakan warisan leluhur yang dimiliki oleh setiap masyarakat Indonesia, kebudayaan merupakan pengetahuan, ide dan hasil cipta masyarakatnya. Sebagai suatu karya seni, musik pada hakikatnya merupakan bagian dari kebudayaan yang tidak terpisahkan dari peradaban manusia, masyarakat atau bangsa. Pada dasarnya karya musik merupakan refleksi perasaan, pikiran atau cerminan realitas sosial dari nilai-nilai kehidupan yang ada dalam masyarakat tersebut. Kehidupan kelompok masyarakat tidak terlepas dari kebudayaannya, sebab kebudayaan ada karena adanya masyarakat pendukungnya.

Salah satunya adalah budaya pada suku Batakyang merupakan suku yang hidup dan berkembang di Provinsi Sumatera Utara, suku Batak terdiri dari Batak Simalungun, Batak Karo, Batak Mandailing, Batak Pakpak Dairi dan Batak Toba. Suku Batak Toba yang pada umumnya mendiami wilayah di sekitar Danau Toba khususnya Kabupaten Toba Samosir.

Dalam adat suku Batak Toba terdapat upacara-upacara atau pesta adat yang khas dan menarik, walapun dalam suku lain terdapat adat seperti ini namun bentuk dan pelaksanaanya sudah pasti berbeda. Misalnya pesta adat pernikahan, pesta sari matua ataupun saur matua, pesta sukuran panen (Gotilon), pesta adat sulang-sulang pahompu,pesta adat sulang hariapan, dan pesta mangongkal holi. Padaawalnya Agama bertentangan dengan upacara adat Batak termasuk upacara adat mangongkal holi tetapi karenaadanya keterkaitan upacara adat dengan pola hidup masyarakat batak, mendorong jemaat untuk mendesak pimpinan gereja mengijinkan kembali pelaksanaan berbagai upacara adat, halini di dukung oleh argumentasi teologis yang dikemukakan para pimpinan rohani tentang keterkaitan injil dengan ajaran Batak, sehingga sampai saat ini masyarakat Batak Toba masih mengakui adanya upacara adat.

Pada zaman dahulu upacara adat Panangkok Saring-saring wajib 
menggunakan Gondang tetapi seiring berjalannya waktu dan tingkat kebutuhan manusia semakin meningkat upacara adat Panangkok Saring-saring ini dapat dibedakan menjadi dua yaitu menggunakan Gondang dan tidak menggunakan Gondang. Pelaksnaan upacara adat ini jika tidak menggunakan gondang maka pesta tersebut disebut dengan pesta hundu latau partangiangan akan tetapi proses adatnya sama dengan upacara adat Panangkok Saring-saring ketika menggunakan gondang, hanya saja tidak ada acara manortor dalam upacara adat tersebut, sehingga proses upacara adat Panangkok Saring-saring tersebut terlaksana dengan cepat. Hal ini diakibatkan karena biaya yang digunakantidak sedikit mengingat kehidupan ekonomi suku Batak secara umum, selain itu butuh kerja sama dan persetujuan yang baik dari semua pihak keluarga, supaya upacara adat ini terlaksana dengan baik.

\section{Sebagaipengiringtortormusik}

Tradisional Batak Toba memiliki peran penting dan kedudukan tersendiri dalam upacara adat atau upacara ritual yang dilaksanakan oleh masyarakat atau suku Batak Toba.
Ketika dalam proses upacara adat Panangkok Saring-saring tesebut memakai gondang, maka gondang yang digunakan adalah bagian dari ansambel Gondang Sabangunan yaitu, Gondang Mula-mula, Gondang Somba-somba, Gondang Mangaliat, Gondang Pasupasu, Gondang Hasahaton Sitiotio. Gondang-gondang ini merupakan reportoar gondang yang terdapat dalam upacara adat Panangkok Saring-saring.

Maka dari penjelasan latar belakang di atas peneliti tertarik untuk mengangkat judul "Bentuk Penyajian Ansambel Gondang Sabangunan Pada Upacara Adat Panangkok Saringsaring Di Desa Partor Janji Matogu Kecamatan Uluan Kabupaten Toba Samosir".

Tujuan penulisan yang ingin dicapai dalam penulisan ini adalah :

1. Untuk mengetahui bagaimana tata pelaksanaan upacara Panangkok Saring-saring.

2. Untuk mengetahui alat musik apa yang digunakan dalam ansambel Gondang Sabangunan dalam mengiringi upacara adat Panangkok Saring-saring.

3. Untuk mengetahui apa kendala yang di hadapi keluarga dalam 
pelaksanaan upacara adat Sampel

Panangkok Saring-saring.

4. Untuk mengetahui bagaimana bentuk penyajian ansambel Gondang Sabangunan pada upacara adat Panangkok Saringsaring.

\section{Lokasi dan Waktu Penelitian}

Sesuai dengan judul penelitian "Bentuk Penyajian AnsambelGondang Sabangunan Pada Upacara Panangkok Saring-saring di Desa Partor Janji Matogu Kecamatan Uluan Kabupaten Toba Samosir". Maka penelitian mengambil lokasi di Desa Partor Janji Matogu Kecamatan Uluan Kabupaten Toba Samosir. Pada bulan NovemberDesember 2015.

\section{Populasi dan Sampel}

\section{Populasi}

Berdasarkan pendapat diatas, yang menjadi populasi dalam penelitian ini adalah Kepala adat atau Pemain musik serta Keluarga yang ikut serta dalam Upacara Manongkal Holi di Desa Partor Janji Matogu Kecamatan Uluan Kabupaten Toba Samosir.
Sampelnya adalah anggota pemain Gondang Sabangunan, Tokoh Adat dan Masyarakat.

\section{Teknik Pengumpulan Data}

Teknik pengumpulan data yang dilakukan adalah sebagai berikut:

1. Observasi

2. Wawancara

3. Dokumentasi

4. StudiKepustakaan

\section{Teknik Analisis Data}

Dalam penelitian ini data yang digunakan adalah teknik analisis data kulitatif dimana proses mencari dan menyusun secara sistematis data-data yang diperoleh dari hasil wawancara, catatan lapangan, dan dokumentasi.

\section{ISI}

Tata Pelaksanaan Upacara Panangkok Saring-saring di Desa Partor Janji Matogu Kecamatan Uluan Kabupaten Toba Samosir

\section{Mangongkal Holi}

Apaun rangkaian acara mangongkal holi sebenarnya dapat di lakukan hanya dalam sehari saja, tergantung cepat atau tidaknya menggali atau mendapatkan kembali tulang belulang yang sudah terkubur bahkan lebih dari puluhan tahun, sehingga acara mangongkal holi 
ini dilaksanakan selama dua hari mulai dari jam 9.00 pagi. Tata upacara mangongkal holi yang terdapat di desa Partor Janji Matogu ini adalah :

a. Sebelum penggalian maka dilaksanakan ibadah di sekitar pemakaman yang dipilih oleh guru huria atau pendeta. Hal ini menunjukkan bahwa masyarakat Partor Janji Matogu termasuk suhut (yang melaksanakan pesta) sudah mempunyai keyakinan sebagai umat Kristen dan tidak bermaksud menyembah berhala tetapi bertujuan untuk menghormati nenekmoyang atau orang tua yang di ambil dari titah ke $\mathrm{V}$ dalam agama Kristen di Partor Janji Matogu tersebut. Bentuk ibadah ini berupa nyanyi bersama, berdoa dan ada khotbah singkat dari pemimpin gereja.

b. Setelah ibadah selesai, sebelum penggalian dimulai maka pihak hula-hula akan memberikan demban/napuran (sirih) dengan ucapan sepatah dua kata semoga penggalian berjalan lancar dan tulang belulang atau saring-saring tersebut bisa segera ditemukan dan tidak memakan waktu lama. c. Pihak keluarga dari bona hasuhuton yang bersangkutan melemparkan uang ke dalam makam. Hal ini dimaksudkan untuk menunjukkan bahwa mereka hadir dalam upacara tersebut, doa supaya tulang belulang keluarga yang bersangkutan cepat ditemukan.

Beberapa hari setelah acara mangomgkal holi, maka pihak kelauarga semua berkumpul dan mengadakan pembicaraan pada malam hari untuk acara yang akan diadakan sehari lagi yaitu pesta atau upacara adat panangkok saringh-saring.

\section{Panangkok Saring-saring}

Gondang dalam upacara Panangkok Saring-saring pada zaman dahulu dilaksanakan tidak hanya pada waktu siang hari saja tetapi dimainkan juga pada malam hari sebelum besoknya acara bahkan ada yang melaksanakannya hingga tiga hari tiga malam. Akan tetapi hal itu tergantung kemampuan pihak keluarga yang mengadakan pesta atau upacara adat. Gondang bisa diadakan hanya pada saat pelaksanaan hanya pada saat pelaksanaan upacara adat tersebut. Jika gondang dibunyikan pada malam hari, maka harus disediakan satu ternak 
lagi yaitu kerbau, sehingga dalam pesta atau upacara adat tersebut membutuhkan dua ekor kerbau. Akan tetapi jika gondang hanya dilaksanakan pada saat Panangkok Saring-saring maka yang di butuhkan hanya satu kerbau yang kemudian disembelih, dimasak dan dimakan bersama dengan para undangan yang akan menghadiri acara tersebut. Sebelum gondang dimainkan oleh pargonsi, masih banyak beberapa proses acara yang harus dimulai.

Keesokan harinya pada pada jam 7 pagi parhobas (para pekerja) sudah mulai sibuk bekerja.Parhobas biasanya warga kampung setempat dan pihak boru (keturunan perempuan yang digali maupun pihak yang menyelenggarakan pesta), penyelenggaraan disebut dengan bona suhut. Sifat gotong royong merupakan salah satu cirri khas masyarakat Partor Janji Matogu, hal ini ditunjukkan lewat pekerjaan yang dilaksanakan parhobas dengan baik dan tanpa pamrih.Sekitar jam 7 pagi tersebut diadakan acara galang raja yaitu memotong kerbau (horbo baratan) dimaksudkan untuk meminta izin dari penetua setempat. Kerbau dalam prosesi acara adat ini akan dijadikan sebagai media persembahan dalam prosesi untuk disajikan bersama-sama kepada seluruh keluarga dan kerabat yang berkumpul, dengan cara dimasak menjadi berbagai hidangan khas daging kerbau. Namun, sebelumnya kegiatan penyembelihan tersebut dilaksanakan, biasanya kerbau yang akan disembelih terlebih dahulu diiringi oleh satu orang penatua adat ataupun pemimpin upacara dengan menggunakan tali pengikat khusus.

Sekitar pukul 8 pagi para undangan mulai berdatangan satu persatu, termasuk para tokoh adat dan hula-hula. Para hula-hula biasanya membawa nasi, beras, ikan mas, dan ulos. Hula-hula adalah tutur yang dihormati dalam batak, karena itu hulahula dianggap memberikan berkat atau pasu-pasu. Oleh karena itu pada saat manortor posisi tangan mereka adalah posisi memberikan berkat, terbuka menghadap ke bawah, sementara boru adalah kerja. Sehingga jika bertemu dengan hula-hula mereka akan bersembah, itu sebabnya dalam manortor dalam posisi tangan mereka diletakkan didahi seperti menyembah.

Setealah itu pihak hula-hula menyerahkan nasi dan ikan mas (dekke sitiotio) kepada sasuhutan yang di sebut acara sulang bao.Sulang baoini 
bertujuan untuk mengawali upacara adat Panangkok Saring-saring tersebut meminta izin kepada hula-hula, supaya direstui membawa tulang belulang yang sudah di dalam peti ke makam yang baru.

Dalam Upacara adat panangkok saring-saring ini terdapat lima reportoar gondang yang berperan dalam acara ini. Yaitu gondang mula-mula, gondang somba-somba, gondang mangaliat, gondang simonang-monang, gondang hasahaton sitiotio.

\section{a. Gondang mula-mula}

Gondang mula-mula merupakan wujud rasa hormat para peserta yang di wakili oleh si peminta gondang kepada tuhan dan sesamanya, serta untuk mengemukakan kepercayaan bahwa segala sesuatu yang ada di dunia ini memiliki asal mula. Gerakan tor-tor pada gondang mulamula antara kaum laki-laki dan perempuan berbeda. Gerakan tor-tor untuk kaum laki-laki adalah dengan mengangkat kedua telapak tangan ke atas namun tidak melebihi kening lalu kedua telapak tangan di rapatkan namun tidak bersentuhan dan jari-jari tangan direnggangkan.
Sedangkan gerakan tor-tor untuk kaum perempuan yaitu dengan merapatkan kedua telapak tangan dan mengangkat posisi tepat didepan dada atau dibawah dagu seperti posisi menyembah. Selanjutnya daun kaki diangkat dan diturunkan sesuai dengan irama dan musik gondangmangaliat yang dimainkan dan diikuti dengan gerakan sembah berirama oleh kedua telapak tangan. Dalam meminta gondang ini terdapat umpasa atau ungkapan yaitu :

"Amang pande nami, sianjur mula-mula sianjur mula tompa, Mula ni nauli pungkontma ulaonta, amang pandenami baen ma gondang mula-mulai”

\section{b. Gondang somba-somba}

Gondang somba-somba bertujuan untuk mengekspresikan rasa hormat kepada sang pencipta dan kepada yang hadir. Berbeda dengan gondang somba-somba pada masa dulu yaitu bertujuan mengekspresikan rasa hormat kepada kekuatan supranatural. Gerakan tor-tor somba untuk lakilaki yaitu kedua tangan diangkat dan telapak tangan dirapatkan kemudian 
ditaruh dikening dengan posisi sembah dan kepala agak menunduk. Sedangkan gerakan tor-tor untuk kaum perempuan yaitu dengan merapatkan kedua telapak tangan dan mengangkat sampai posisi tepat didepan dada atau di bawa dagu seperti posisi menyembah dan kepala agak menunduk. Selanjutnya daun kaki diangkat dan diturunkan sesuai irama dari musik gondang yang dimainkan dan diikuti dengan gerakan sembah berirama olehkedua telapak tangan. Dalam meminta gondang terdapat umpasa atau ungkapan yaitu :"Amang pande nami, tabo tuak tangkasan molo masuk tu rura ni toba, Jonjong hami dison alai jumolo hami marsomba, Paboahon tu na torop asa marsomba hami tu jahowa, Amang pande nami baen damang ma jo gondang somba-sombai"

\section{c. Gondang mangaliat}

Masyarakat desa Partor Janji Matogu memberi pengertian bahwa gondang mangaliat itu merupakan gondang permintaan agar bona hasuguton (yang mengadakan) diberikan kekayaan, kesehatan, anak cucu, dan lain-lain. Pada repotoar ini irama musik cepat dan bona hasuhutan akan manortor (menari) sambil mengelilingin rudangrudangdalam upacara adatpanangkok saring-saring tersebut, posisi tangan menyembah terletak sejajar dengan dada.

\section{d. Gondang pasu-pasu}

Gondang Pasu-pasu merupakan gondang untuk memberikan pasupasu proses memberi berkat ini dengan cara mengusap bagian kepala serta meletakkan ujung ulos yang dinkenakan. Dalam gondang dan gerakan tor-tor ini dapat melihat sistim kekerabatan masyarakat batak toba yaitu dalihan natolu, begitu juga terlaksana rangkaian upacara adat panangkok saring-saring ini. Dalam meminta gondang mangaliat ini juga sipeminta gondang.

\section{e. Gondang hasahatan sitio-tio}

Gondang hasahatan memiliki makna seluruh permintaan dan permohonan telah disampaikan kepada tuhan dengan harapan agar semua permohonan tersebut dikabulkan.Pada acara adat ini tidak jarang gondang sitio-tio langsung disambung setelah gondang 
Gondang ini merupakan gondang penutup dari seluruh rangkaian acara.Setelah rombingan hula-hula, hasuhuton dan boru yang mengusung peti ke makam yang baru sampai ke tempat tersebut, kemudian satu persatu peti tersebut dimasukkan kedalam makam yang di sebut dengan batu na pir atau tambak na timbo. Setelah semua peti di masukkan selanjutnya pihak hulahula berdiri di lokasi makam atau naik ke atas untuk mengungkapkan sepata dua kata yaitu berupa petuan atau nasehat kepada hasuhuton yang berada di depan makam tersebut.

Pada saat itu hula-hula biasanya akan meminta tanda terimakasih dari pihak bona hasuhuton berupa uang dalam amplop dengan nilai tidak ditentukan nilainya. Pada umumnya acara ini meskipun sama-sama acara masyarakat batak toba, akan tetapi selalu ada perbedaan tatacara tergantung tata acara kampung setempat misalnya didaerah partor janji matogu bisa berbeda dengan desa yang bersebelahan dengan desa Partor Janji Matogu.

Acara memindahkan peti yang berisi Saring-saring ke lokasi makam yang baru atau acara Panangkok Saring- saring tersebut dilanjutkan dengan pesta adatnya salah satunya adalah menunjukkan peranan penting Gondang Mangaliat dalam acara adat tersebut. Setelah bona hasuhutan dan hula-hula sampai di lokasi pesta, kemudian hasuhutan meminta kepada pargonsi atau pemusik untuk memainkan gondang kembali. Pembukaan gondang dalam upacara ini disebut dengan gondang alualu atau yang disebut dengan Mambuat tua ni gondang. Pihak hasuhutan akan meminta kepada pargonsi untuk memainkan gondang yang bertujuan untuk memohon berkat dari tuhan untuk acara yang sedang dilaksanakan. Kemudian pargonsi meminkan gondang untuk mengelu-elukan dan sebagai pemberitahuan dan permohonan secara musikal kepada Tuhan Yang Maha Esa agar acara gondang direstui.

Selanjutnya protokol atau parhata dalam acara tersebut melanjutkan kembali meminta kepada pargonsi untuk memainkan gondang gondang dengan memberkan sepatah dua kata yakni permohonan izin kepada roh nenek moyangdan mengeluelukan khalayak ramai atau undangan sebagai 
pemberitahukan dan permohonan izin untuk memulai acara gondang tersebut.

Akhir dari gondang hasahaton ditandai dengan mengucapkan kata "horas" sebanyak tiga kali dan sambil mengangkat ujung ulos ke atas. Urutan gondang yang dimainkan pada acara penutupan ini sama halnya dengan pembukaan. Dengan berakhirnya seluruh rangkaian acara dalam penutupan acara adat panangkok saring-saring ini, maka secara resmi acara atau upacara adat panangkok saring-saring tersebut telah selesai.

Alat Musik Yang Di Gunakan Dalam Ansambel Gondang Sabangunan Untuk Mengiringi Upacara Adat Panangkok Saring-saringDi Desa Partor Janji Matogu Kecamatan UluanKabupaten Toba Samosir

Ansambel Gondang Sabangunan terdiri dari dari beberapa alat musik yaitu :Sarune Bolon, Taganing, Gordang, Ogung dan Hesek (wawancara dengan bapak marolop marbun pemain taganing)

\section{a. Sarune Bolon}

Sarune Bolon (aerophone double reed) adalah alat musik tiup yang paling besar yang terdapat pada masyarakat Toba. Alat musik ini digunakan dalam ensambel musik yang paling besar juga, yaitu Gondang bolon (artinya : ensambel besar).

\section{b. Taganing}

Taganing adalah drum set melodis (drum-chime), yaitu terdiri dari lima buah gendang yang gantungkan dalam sebuah rak. Bentuknya sama dengan gordang, hanya ukurannya bermacammacam.

\section{c. Gordang}

Gordang adalah gendang yang paling besar yang terdapat pada masyarakat Batak Toba, yaitu gendang yang diletakkan pada sebelah kanan pemain di rak gendang tersebut.Gordang ini biasanya dimainkan oleh satu orang pemain dengan menggunakan dua buah stik.

\section{d. Ogung:}

1. Oloan

Oloan adalah salah satu gung berpencu yang terdapat pada Batak Toba. Oloan dimainkan secara bersamaan dengan tiga buah gung yang lain dalam satu ensambel, sehingga jumlahnya empat buah, 
yang juga dimainkan oleh empat orang pemain.

\section{Panggora}

Panggora juga adalah satu buah gong yang berpencu yang dimainkan oleh satu orang. Bunyi dari gung ini adalah ' pok'. Bunyi ini timbul adalah karena gong ini dimainkan dengan memukul pencunya dengan stick sambil berdiri dan sisi gong tersebut dimute(diredam) dengan tangan.

\section{Doal}

Doal juga adalah gong berpencu yang dimainkan secara bersahutsahutan dengan panggora dengan bunyi secara onomatopenya adalah kel sehingga apabila dimainkan secara bersamaan dengan gong panggora akan kedengaran pok - kel - pok - kel dan seterusnya dengan ritem yang tidak berubah-ubah sampai kompisisi sebuah gondang (lagu) habis.

\section{e. Hesek}

Hesek adalah instrumen musik pembawa tempo utama dalam ensambel musik gondang sabangunan.Hesek ini merupakan alat musik perkusi konkusi.Hesek ini terbuat dari bahan metal yang terdiri dari dua buah dengan bentuk sama, yaitu seperti cymbal. Namun sekarang ini alat musik ini terkadang digunakan sebuah besi saja, bahkan kadang-kadang dari botol saja.

\section{f. Odap}

Odapadalah gendang dua sisi berbentuk konis. Odap juga terbuat dari bahan kayu nangka dan kulit lembu serta tali pengencang/pengikat terbuat dari rotan.Ukurantingginya lebih kurang $34-37 \mathrm{~cm}$, diameter membran sisi satu $26 \mathrm{~cm}$, dandiametermembran sisi 2 lebih kurang $12-14 \mathrm{~cm}$.Cara memainkannya adalah, bagian gendang dijepit dengan kaki, lalu dipukul dengan alat pemukul, sehingga bunyinya menghasilkan suara dap.., dap..., dap.., dan seterusnya. Alat musik ini juga dipakai dalam ensambel gondang sabangunan.

Kendala Yang di Hadapi Keluarga Dalam Pelaksanaan Upacara Adat Panangkok Saring-saring di Desa 
Partor Janji Matogu Kecamatan Uluan Kabupaten Toba Samosir

Dalam pelaksanaan upacara Panangkok Saring-saring di perlukan waktu yang tidak sedikit, perlu tiga bulan persiapan, dikarenakan banyaknya kendala yang akan di hadapi, mulai dari pengumpulan pomparan (keturunan), karena tidak adanya waktu yang tepat untuk mengumpulkan smua pomparan, penyediaan alat dan pemusik, meminta kepada parsahutaon (satu kampung) untuk membantu demi kelancaran upacara panangkok saring-saring, parhobasmemasak (pekerja), sampai ke masala keuangan, karena dalam dalam upacara panangkok saring-saring ini diperlukan dana yang cukup besar.

Bentuk Penyajian Ansambel Gondang Sabangunan pada upacaraadat Panangkok Saringsaring di desa Partor Janji Matogu Kecamatan Uluan Kabupaten Toba samosir

Setelah melakukan penelitian, pada upacara adat Panangkok Saring-saring, ternyata ada beberapa hal yang harus di ketahui yaitu, sebelum proses adat panangkok Saring-saring maka terlebih dahulu diadakan, acara martonggo raja oleh suhut dan raja hata. Peserta tonggo raja/ marria terdiri dari bona hasuhuton, hula-hula, boru, dongan sahuta, acara ini diadakan untuk menentukan tanggal yang sesuai untuk melaksanakan acara mangongkal holi dan panangkoksaringsaring, menentukan jumlah undangan, menentukan hewan apa yang akan disembelih, dan menentukan syarat margondang dalam upacara adat panangkok saring-saring. Sebelum mangongkal holi akan dilakukan ibadah disekitar makam yang akan digali yang dipimpin oleh guru huria (pendeta). Mangongkal holi (menggali tulang belulang) lalu di pindahkan kedalalam keranjang untuk di naikkan kedalam tugu/batu na pir. Panangkok saringsaring yaitu menaikkan tulang belulang ke dalam tugu/batu na pir dengan poses adat.

\section{PENUTUP}

\section{Kesimpulan}

Dari uraian-uraian tentang permasalahan dan pembahasan yang telah dikemukaka pada bab-bab sebelumnya, maka pada bab ini penulis mencoba membuat kesimpulan mengenai bentuk dan penyajian musik ansambel Gondang Sabangunan Pada 
Upacara Panangkok Saring-saring di Desa Partor Janji Matogu Kecamatan Uluan Kabupaten Toba Samosir

1. Anansambel Gondang Sabangun masih berperan penting dalam upacara adat di desa PartorJanjiMatogu terutama dalam upacara adat Panangkok saring-saring. Upacara adat mangongkal holi(menggali tulang belulang) merupakan bagian dari acara panangkok saring-saring, ketika saringsaring sudah digali kemudian dipindahkan ke makam yang baru. Acara memindahkan saring-saring ini disebut dengan panangkok saring-saring. Acara ini terbagi dalam dua bagian yaitu ketika acara panangkok saring-saring tidak menggunakan musik berupa gondang maka acara tersebut disebut dengan pesta hunduldan ada juga yang menyebutnya dengan partangiangan. Susunan acara adatnya tetap sama hanya saja perbedaannya dilihat dari segi penggunaan gondang dalam mengiringi acara ini.
2. Ansambel gondang sabangunan yang digunakan dalam mengiringi upacara panangkok saring-saring ialah Gondang Mula-mula, Gondang Sombasomba, Gondang Mangaliat, Gondang Pasu-pasu, Gondang Hasahaton Sitiotio.

3. Alat musik yang di gunakan dalam upacara adat panangkok saring-saring yaitu sarune bolon, ogung, taganing, gordang, hesek dan odap.

\section{Saran}

1. Kepada seluruh lapisan masyarakat Batak Toba terutama generasi penerus jangan pernah melupakan alat-alat musik tradisional. Ketika kita mempunyai waktu dan kesempatan ada baiknya kita juga berusaha mempelajari cara memainkan alat musik batak toba tersebut. Dalam pembahasan ini peneliti sangat sulit untuk mendapatkan buku tentang masyarakat Batak Toba sebagai bahan referensi terutama tentang upacara adat yang terdapat dalam masyarakat batak toba, oleh karena itu sangat diharapkan 
kepada para petuah adat (orang yang mahir dan mengerti tentang adat-istiadat etnis Batak Toba) untuk menuangkan ilmunya tentang adat-istiadat etnis Batak Toba.

\section{DAFTAR PUSTAKA}

Arikunto, Suharsimi, 2006, Dasar-dasar Evaluasi Pendidikan, Edisi Revisi, cet.6, Jakarta: Bumi Aksara.

Aritonang. Jan, dkk.2006. Beberapa pemikiran menuju teologi dalihan Na Tolu. Jakarta: Dian Utama.

Bungin, Burhan. 2011. Penelitian Kualitatif. Jakarta: Kencana.

Basrowi \& Suwandi. (2008). Memahami Penelitian Kualitatif. Jakarta: Rineka Cipta.

Djelantik, A.A.M. 2000. Estetika Sebuah Pengantar. Bandung: Masyarakat Seni Pertunjukan Indonesia.

Djelantik, AAM. 1990. Pengantar Pasar Estetika. Denpasar: STSI Denpasa.

1999. Estetika. Bandung: Masyarakat Seni Pertunjukan Indonesia.

Hadi, Y. Sumandiyo.2000. Seni Dalam Ritual Agama. Yokyakarta: Yayasan untuk Indonesia.
Hutabarat, Marajohan. 2009. Pelaksanaan adat Dalihan Natolu. Jakarta : Balai Pustaka.

James, Hendry. 2000. Filsafat Batak, Tentang Kebiasaan-kebisaan Adat-Istiadat Batak. Jakarta : Sinar Harapan.

Langer, Susanne K. 1998. Rout-Ledge Encyclopedia of Philosophy. London

Mack, Dieter. 2001. Pendidikan Musik: Antara Harapan Dan Realita. Bandung: Universitas Pendidikan Indonesia.

Maulima, Pasar. 2011. Metodologi Penelitian Pendidikan. Medan: Fakultas Matematika dan Ilmu Pengetahuan Alam Universitas Negeri Medan.

Miller. 2002. "The Rule Of Music In My Life" : Quantum teaching.

Maduma, Tien. 2012. Karakter Musikal Gondang Husip-husip Pada Group Poster Sihotang di Tapanuli Utara. Medan. Skripsi untuk Mendapatkan.Gelar Sarjana Pendidikan Universitas Negeri Medan.

Nana Syaodih Sukmadinat. 2012. Metode Penelitian Pendidikan. Bandung: PTRemaja Rosdakarya Offset.

Pasaribu, Ben $\quad 2004$. Musikalitas + Etnisitas $=$ Pluralitas Dalam Musik Etnik. Medan: Pusat Dokumentasi Kebudayaan Batak HKBP Nomensen. 
Pasaribu, Sharon Rose (2014). Bentuk Penyajian Gondang Malim Pada Upacara Ritual Parmalim Si Inum Uras Di Kecamatan Pintu Pohan Meranti Kabupaten Toba Samosir. Medan : Skripsi untuk Mendapatkan Gelar Sarjana Pendidikan Universitas Negeri MedanSilitonga, Pita Hotma Dameria.2014. Teori Musik.Medan: Unimed Press.

Silitonga, Pita Hotma Dameria.2014. Teori Musik.Medan: Unimed Press.

Sinaga, Richard. 2013. Meninggal Adat Dalihan Natolu. Jakarta : Dian Utama.

Sugiyono.2011. Metode Penelitian. Bandung: Alfabeta.

soeharto, M. 1992. Kamus Musik. Jakarta: Gramedia Widiasarana.

Surya, Brata Addy. 2012. Jenis-jenis alat musik. Jakarta : Bumi Pustaka.

Situmorang, Jaulahan. 1992. Penuntun Adat Praktis. Pematang Siantar.

Sipayung, Hernauli dan S. Andreas Lingga, 1994. Ragam Hias (Ornamen) Rumah Tradisional Simalungun. Medan.

S. Yetty. (2009). Perbedaan Gondang Hasapi dan Gondang Sabangunan Pada Masyarkat Batak Toba Dengan Fokus Perhatian Pada Upacara Adat Perkawinan dan Kematian. Medan. Skripsi untuk Mendapatkan Gelar Sarjana
Pendidikan Universitas Negeri Medan.

Sinaga. Tiodora. (2013). Keberadaan Gondang Naposo Pada Masyarakat Batak Toba Di Desa Sei Muka Kecamatan Talawi Kabupaten Batubara. Medan. Skripsi untuk Mendapatkan Gelar Sarjana Pendidikan Universitas Negeri Medan.

Sinaga, Delfiana (2015). “Gondang Hasapi Pada Acara Ritual Parmalim Si Pahasada Di Huta Tinggi Kecamatan Laguboti Kabupaten Toba Samosir (Kajian Bentuk Penyajina dan Fungsi. Skripsi untuk Mendapatkan.Gelar Sarjana Pendidikan Universitas Negeri. 